\title{
Androgen and Estrogen Treatment, Alone or in Combination, Differentially Influences Bone Maturation and Hypothalamic Mechanisms that Time Puberty in the Male Rhesus Monkey (Macaca mulatta)
}

\author{
MATTHEW O. FRASER, MUHAMMAD ARSLAN, AND TONY M. PLANT \\ Department of Cell Biology and Physiology [M.O.F., T.M.P.], University of Pittsburgh School of \\ Medicine, Pittsburgh, PA 15261; Division of Urology [M.O.F.], Department of Surgery, Duke University \\ Medical Center, Durham, NC 27710; and Pakistan Academy of Science [M.A.], Islamabad, Pakistan
}

\section{ABSTRACT}

\begin{abstract}
In higher primates, the mechanisms that govern the ontogeny of gonadotropin-releasing hormone pulse generator activity and that, therefore, dictate the timing of the onset of puberty remain intriguingly elusive. Groups of three infant agonadal male monkeys were treated with sex steroids $\left[17 \beta\right.$-estradiol $\left(\mathrm{E}_{2}\right)$, testosterone (T), or dihydrotestosterone (DHT)] for the first year of life to advance bone age (BA). $E_{2}$ and $T$ resulted in a significant advancement of BA, and a pubertal BA of $130 \mathrm{wk}$ was attained at a mean chronological age of 64 and 67 wk, respectively. In contrast, DHT failed to advance BA during treatment but stimulated linear growth. All animals exhibited a pubertal resurgence in LH secretion, but the timing of this developmental event did not differ between treatment and control groups (the mean for all animals was $117.7 \pm 8.9$ wk). Two of the three T-treated animals, however, displayed a pubertal LH resurgence at a remarkably young age (70 and $76 \mathrm{wk}$ of age) that coincided with $\mathrm{T}$ withdrawal. During the period of steroid treatment, all three groups were significantly heavier than the controls. The rate of body weight gain was most rapid in the DHT-treated group. Steroid treatments also resulted in accelerated linear growth.
\end{abstract}

Body weight gain and linear growth continued at the same rate as controls after withdrawal of treatment. These data indicate that attainment of a pubertal BA may be a necessary but not a sufficient factor to trigger the onset of puberty. The results not only are consistent with the view that androgen-induced skeletal maturation in males is mediated by estrogen receptor activity but also indicate that androgen receptor activity contributes to the pubertal growth spurt in males. (Pediatr Res 57: 141-148, 2005)

AR, androgen receptor
BA, bone age
CA, chronological age
CRL, crown-to-rump length
DHT, dihydrotestosterone
ER, estrogen receptor
$\mathbf{E}_{\mathbf{2}}$, estradiol
GnRH, gonadotropin releasing hormone
SA, size age
T, testosterone

Puberty in humans is composed of two developmental processes: gonadarche and adrenarche (1). The pivotal of these two developmental events, gonadarche, is triggered by a resurgence in pulsatile gonadotropin-releasing hormone $(\mathrm{GnRH})$ release, which

Received December 5, 2003; accepted June 18, 2004

Correspondence: Tony M. Plant, M.D., Department of Cell Biology and Physiology, University of Pittsburgh School of Medicine, S-828A Scaife Hall, Pittsburgh, PA 15261; e-mail: Plant1@ pitt.edu

This study was supported by National Institutes of Health Grants R01 HD13254 and U54 HD08610.

A preliminary report of this work was presented at the Midwest Society for Pediatric Research, November 1988, Chicago (Abstract 3:901A), and at the 71st Annual Meeting of The Endocrine Society, June 1989, Seattle (Abstract \#1174).

DOI: 10.1203/01.PDR.0000148063.68338.A0 has been held in a state of check since infancy (2). It has long been assumed that a certain degree of growth and somatic maturation must be achieved for puberty to unfold (3), and the concept of a central neural growth-tracking mechanism or somatometer capable of coordinating the pubertal resurgence of pulsatile GnRH release with the attainment of an adult soma has been postulated (4). Several putative peripheral signals of somatic development that may be tracked by the somatometer have been proposed. It has been argued that changes in the fat:lean ratio during development modify circulating levels of gonadal hormones, which, in turn, influence the brain (5). It has also been suggested that the somatic signal may be mediated by a change in circulating concentrations of a metabolic substrate or hormone (6). The 
observations in humans that relate maturation of the skeleton to the onset of puberty $(7,8)$ provide a third possibility: that a substance that is synthesized and secreted by developing bone may be responsible for imposing the prepubertal hiatus in pulsatile $\mathrm{GnRH}$ release. In a normal population, the temporal sequence of postnatal developmental changes in the skeleton are related to chronological age (CA); therefore, all stages of skeletal maturity may be expressed as bone age (BA) $(9,10)$. In this regard, it of interest to note that in both human and nonhuman primates, the earlier onset of puberty in females is associated with a more rapid rate of skeletal maturation $(11,12)$ and that menarche in girls is more tightly coupled to BA than it is to CA $(7,8)$. Moreover, in children with constitutional delay of growth and maturation or true isolated growth hormone deficiency, gonadarche occurs at a late CA but at normal BA (13). Conversely, when skeletal maturation is advanced early in life as a result of chronic exposure to high levels of androgens that result from endocrinopathies such as congenital adrenal hyperplasia $(14,15)$ and familial testotoxicosis $(15,16) \mathrm{GnRH}$-dependent precocious gonadarche may be observed. Here it should be noted that the association between BA and puberty may reflect the effect of sex steroids on BA rather than the effect of bone maturity on puberty. Although the correlation between BA and the onset of puberty is well documented, it has been historically dismissed as a possible causal event leading to the onset of sexual maturation (17). Very recently, however, Flor-Cisneros et al. (15) suggested that the synchrony between maturation of the skeleton and the hypothalamicpituitary-gonadal axis in boys with abnormal developmental tempo is consistent with the hypothesis that skeletal maturation influences hypothalamic-pituitary-gonadal axis maturation. In this regard, bone and epiphyseal cartilage produce and release peptides into the systemic circulation $(18,19)$, and these or other factors therefore might serve as endocrine cues of bone maturation.

In an attempt to address the possible role that skeletal maturation may play in the timing of the onset of gonadarche in higher primates, the present study of the rhesus monkey was conducted to determine whether hormonally induced changes in skeletal maturation are associated with alteration in the timing of the onset of the pubertal resurgence in pulsatile GnRH release. Small groups of agonadal male monkeys were treated with $17 \beta$-estradiol $\left(\mathrm{E}_{2}\right)$, testosterone $(\mathrm{T})$, or dihydrotestosterone (DHT) for periods of 55-70 wk. The animals were followed thereafter until the pubertal resurgence of pulsatile GnRH release, as reflected by circulating LH concentrations, was identified. Weekly blood samples were taken to monitor steroid and gonadotropin concentrations. Approximately monthly measures of body weight, crown-to-rump lengths (CRLs), and X-rays of the hands and wrists were taken to relate these indices of growth and somatic development to the time of the pubertal resurgence of pulsatile LH secretion.

\section{METHODS}

\section{Animals}

Twelve neonatal male rhesus monkeys, produced by the breeding program of the Center for Research in Reproductive Physiology, were maintained as previously described (20) in a controlled photoperiod (lights on 0600-1800 h).
Neonates were housed with their mothers until 24 wk of age, at which time they were separated from their mothers and subsequently housed with an age-matched female. Food (Lab Diet Purina Monkey Chow \#5045; PMI Nutrition Int., Inc., Brentwood, MO) and water were provided ad libitum. Fresh fruits and vegetables were provided as a nutritional supplement. Morning blood samples $(3 \mathrm{~mL})$ were collected as plasma by femoral venipuncture at weekly intervals, and plasma was stored at $-20^{\circ} \mathrm{C}$ until assayed. The animals received an i.m. injection of $25 \mathrm{mg}$ of Iron-Dextran (Phoenix Pharmaceuticals, Inc., St. Joseph, MO) once a month to maintain hematocrit. The animals were maintained in accordance with National Institutes of Health Guidelines for the Care and Use of Experimental Animals, and the experiments were approved by the University of Pittsburgh Institutional Animal Care and Use Committee.

\section{Hormone Assays}

Plasma $\mathrm{T}$ and DHT were measured using a previously described RIA system that uses antibody GDN S-250 and detects both androgens (20). The interassay and the average intra-assay coefficients of variation for the androgen RIA were 9.6 and $8.0 \%$ (range $2.3-18.7 \%$ ), respectively. $\mathrm{E}_{2}$ was assayed using a previously described RIA that uses antibody GDN-244 (21). Plasma LH was measured using a previously described RIA (22) that uses a cynomolgus LH-anti-human CG antibody (R13) and rhesus pituitary LH preparation, WDP-Rh-LH-RP-1, as standard. The sensitivity of the LH assay ranged from 6.1 to $13.7 \mathrm{ng} \mathrm{LH} / \mathrm{mL}$ plasma. The interassay coefficient of variation was $1.4 \%$, and the intra-assay coefficient of variation was $7.8 \%$.

\section{Steroid Treatments}

Steroid treatment was achieved using s.c. implanted Silastic capsules. For $\mathrm{E}_{2}$ treatment, implants were made from 2-cm lengths of Silastic tubing (ID = 0.062 in and $\mathrm{OD}=0.125 \mathrm{in}$ ). For androgen treatments, 2 - to 4-cm lengths of Silastic tubing $(\mathrm{ID}=0.132$ in and $\mathrm{OD}=0.183 \mathrm{in}$ ) were used. Control animals received empty Silastic capsules. All steroids were purchased from Sigma Chemical Co. (St. Louis, MO).

\section{Parameters of Somatic Development}

Linear dimension and body weight. CRL was measured under ketamine sedation (40-60 mg/kg i.m.; Vetalar; Parke-Davis \& Co., Morris Plains, NJ) using a custom-designed device that allowed the animals to be positioned in a consistent manner for each measurement. Body weight was measured using a top-loading scale.

Bone age. X-rays of the hands and wrists were taken while the animals were sedated for measurement of linear dimensions. For this purpose, the hands and wrists were positioned on a photographic plate and the rest of the body was protected from radiation by a lead shield. BA was estimated from X-rays using the atlas of Michejda (12) for the rhesus monkey. In this procedure, the size and shape of various carpal ossification centers and the order of appearance of epiphyseal fusion are evaluated qualitatively. This atlas is based on gonadally intact monkeys, and, for the present purpose, skeletal maturation in agonadal and intact animals before the pubertal resurgence of hypothalamic $\mathrm{GnRH}$ release was assumed to be comparable.

Size age. The relationship between body weight and CA in agonadal male rhesus monkeys was established using data from the present control animals, in combination with those obtained from similar monkeys in a previous study (20). This relationship provided a standard curve from which to obtain a post hoc estimate of size age (SA) for the steroid-treated animals (Fig. 1).

\section{Experimental Design}

At 1-3 wk of age, neonatal monkeys were bilaterally orchidectomized under ketamine anesthesia (125 mg/kg) using sterile technique. At the time of surgery, the experimental animals received an s.c. implant of steroidcontaining Silastic capsules. Control animals received an implant of blank Silastic capsules. Capsule dimensions that produced plasma $\mathrm{E}_{2}$ concentrations of $\sim 0.3 \mathrm{nM}$ [within the range of late follicular-phase serum concentrations in adult female rhesus monkeys (23)] and plasma androgen concentrations of $\sim 70$ $\mathrm{nM}$ [comparable to peak nocturnal testosterone concentrations in normal adult male rhesus monkeys; (21)] in $\mathrm{E}_{2^{-}}$and T-treated animals, respectively, were 


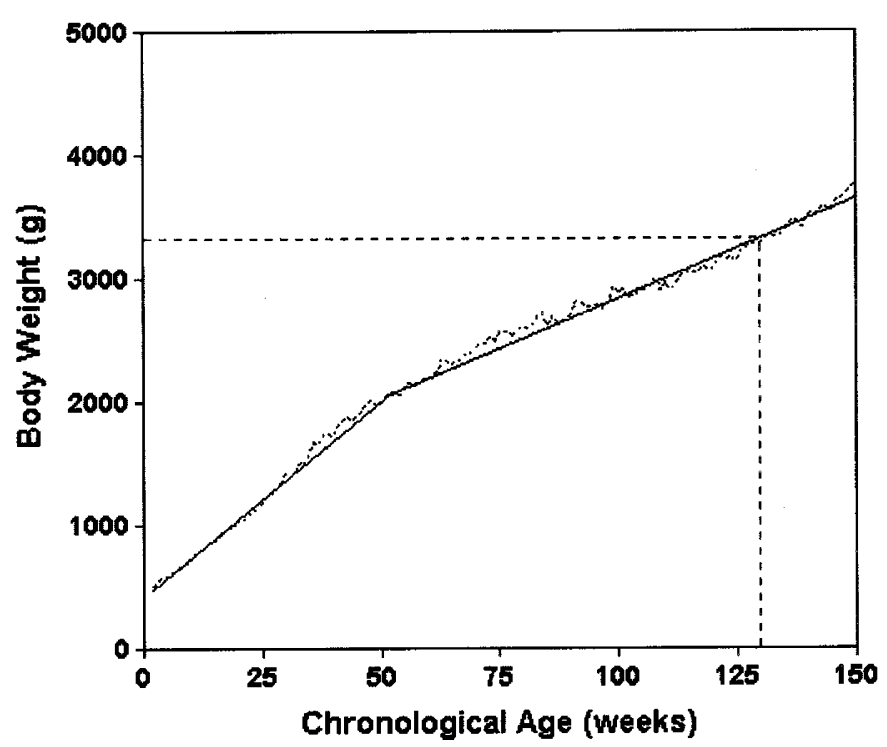

Figure 1. The relationship between body weight and CA that was used as the standard curve for estimating SA. The solid line is the combination of two linear regressions from 2-53 and 53-150 wk of age of five-point smoothed, mean body weight data from the two control animals of this study and four similar animals from a previous study (20). The overlying dotted line represents the mean data $(n=6)$ from which the standard curve was derived. The vertical and horizontal stippled lines illustrate that an animal with a body weight of $3315 \mathrm{~g}$ is assigned an SA of $130 \mathrm{wk}$.

selected. $\mathrm{E}_{2}$ levels were not measured in T-treated monkeys. Blood samples were collected weekly, and, when so indicated by RIA results, the number of steroid-containing capsules was adjusted to maintain the desired circulating steroid concentrations. Body weight was assessed weekly, and BA and other somatic measurements were taken once a month

The pubertal resurgence of hypothalamic GnRH as reflected by LH release occurs at a CA of $\sim 130 \mathrm{wk}$ in untreated agonadal male rhesus monkeys (20); therefore, the intent of the steroid treatments was to achieve a BA of $130 \mathrm{wk}$ precociously. Upon attainment of this target BA, steroid-containing Silastic capsules were removed and blood samples were taken at weekly intervals to monitor plasma $\mathrm{LH}$ concentrations. The resurgence of $\mathrm{LH}$ secretion was formally identified by a modification of a previously described algorithm (24). The threshold value by which circulating LH concentrations ( 5 wk moving average) had to increase, however, was elevated from 1.75-2.25 to reduce false positives that might arise from the less frequent assessment of circulating $\mathrm{LH}$ concentrations in the present study. Animals in each group were tracked until the entire group had exhibited a resurgence in LH secretion, and the overall duration of the study differed between groups.

\section{Numerical Analysis}

Data were analyzed using linear regression, two-way ANOVA, or the $t$ test. The ANOVA calculations did not include repeated measures as a parameter because the low numbers of animals per group did not warrant the additional statistical power afforded by this method. For numerical analysis of the BA data, the X-rays were coded and re-read in a blinded manner. For statistical analyses, all somatic development data were organized by treatment and posttreatment periods. A $p<0.05$ was considered significant. During the course of the study, one control animal and one DHT animal were lost to unidentified illness (at 72 and 118 wk of age, respectively).

\section{RESULTS}

Effects of gonadal steroid treatments on BA. As anticipated, BA in control animals progressed in a linear manner $\left(r^{2}\right.$ $=0.97$ ) until a CA of $130 \mathrm{wk}$ (the pubertal BA). $\mathrm{E}_{2}$ and $\mathrm{T}$ treatments resulted in a significant advancement of BA (Fig. 2),

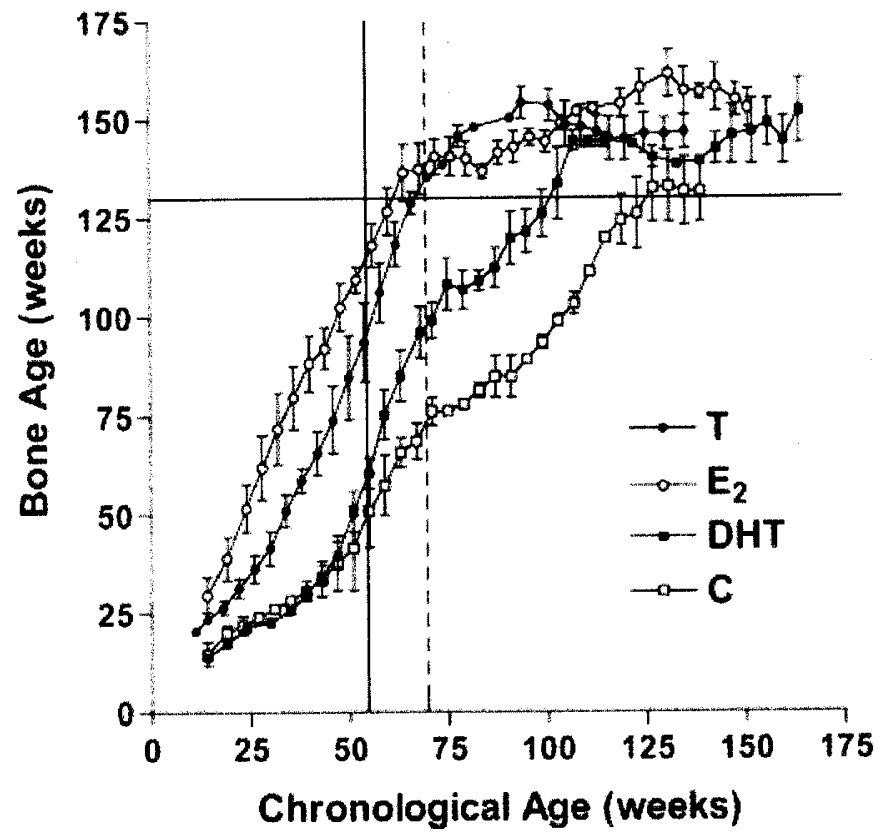

Figure 2. Mean ( \pm SEM) BA estimates from 10 to up to $165 \mathrm{wk}$ of age for agonadal male rhesus monkeys that received $\mathrm{E}_{2}$ treatment $(\mathrm{O} ; n=3)$, DHT treatment ( $\square, n=3$ until wk 118), or blank capsules (C; $\square$; $n=3$ until wk 72) from $1-3$ to $55 \mathrm{wk}$ of age or $\mathrm{T}$ treatment $(; n=3)$ from $1-3$ to $70 \mathrm{wk}$ of age. The vertical lines indicate the CAs at the times of treatment cessation (solid $=55 \mathrm{wk}$, dashed $=70 \mathrm{wk}$ ). The horizontal line represents the target pubertal BA of $130 \mathrm{wk}$. The slope of the regression of BA upon CA during treatment with $\mathrm{E}_{2}$ or $\mathrm{T}$ was significantly different $(p<0.05)$ from that of control (blank capsules, C).

as reflected by a significantly greater slope of the regressions of BA upon CA during steroid treatment $(p<0.05)$ and by monthly BA values greater than those of controls $(p<0.05)$. In $\mathrm{E}_{2^{-}}$and T-treated animals, the pubertal BA of 130 wk was attained at a CA of $64.0 \pm 3.5$ and $66.6 \pm 1.4 \mathrm{wk}$ (mean \pm SEM), respectively. It should be noted that, in the $\mathrm{E}_{2}$-treated group, steroid capsules were removed at 55 wk of CA (i.e. before the attainment of the pubertal BA) on the basis of BA assessments made at that time and before $\mathrm{X}$-rays were blinded for formal analysis. The steroid-containing capsules from Ttreated monkeys were removed at a CA of $70 \mathrm{wk}$, i.e. immediately after attaining a pubertal BA. In striking contrast to the effects of $E_{2}$ and $T$, DHT treatment for 55 wk failed to significantly advance BA (Fig. 2). However, BA in DHTtreated animals did seem to diverge from the control group during the last 5-10 wk of treatment, and withdrawal of this steroid was associated with a robust acceleration in skeletal maturation (Fig. 2). This effect of DHT withdrawal was reflected by a significantly greater slope of the regression of BA upon CA during the first year after DHT withdrawal when compared with the corresponding period for controls $(p<$ 0.05). By 99 wk of CA, the DHT-treated animals had attained the pubertal BA (Fig. 2). After attainment of the pubertal BA in all groups, BA advancement seemed to plateau (Fig. 2).

Effect of gonadal steroid treatments on the timing of the pubertal resurgence in LH secretion. All animals exhibited a pubertal resurgence in LH secretion, and there were no significant differences between groups in the timing of this devel- 
opmental event $(119.7 \pm 11.2,94.7 \pm 21.7,144.0 \pm 7.3$, and $123.0 \pm 8.2 \mathrm{wk}$ for $\mathrm{E}_{2}, \mathrm{~T}, \mathrm{DHT}$, and control animals, respectively). When data from individual monkeys were examined, however, it became evident that two of the three T-treated animals exhibited a pubertal resurgence in $\mathrm{LH}$ secretion at a remarkably young CA of $73.0 \pm 3.0 \mathrm{wk}$ (Fig. 3 for example). This coincided with withdrawal of $\mathrm{T}$ treatment. The pubertal mode of LH secretion in these two animals was interrupted by a transient hiatus between $\sim 90$ and 120 wk of CA (see Fig. 3 for example).

Effect of gonadal steroid treatments on SA. All steroid treatments advanced SA in a linear manner $(p<0.05)$, and this progression was maintained after steroid withdrawal (Fig. 4). The pubertal SA in the $\mathrm{E}_{2}, \mathrm{~T}$, and DHT groups was achieved at a significantly $(p<0.05)$ earlier CA $(89.6 \pm 8.2,91.3 \pm 23.4$, and $115.5 \pm 62.6 \mathrm{wk}$, respectively) than in the control group $(151.0 \pm 9.0 \mathrm{wk})$. SA progression in control animals was also linear throughout the course of the study $\left(r^{2}=0.99\right)$. Unlike BA, SA continued to advance beyond attainment of pubertal $\mathrm{SA}$ in all animals.
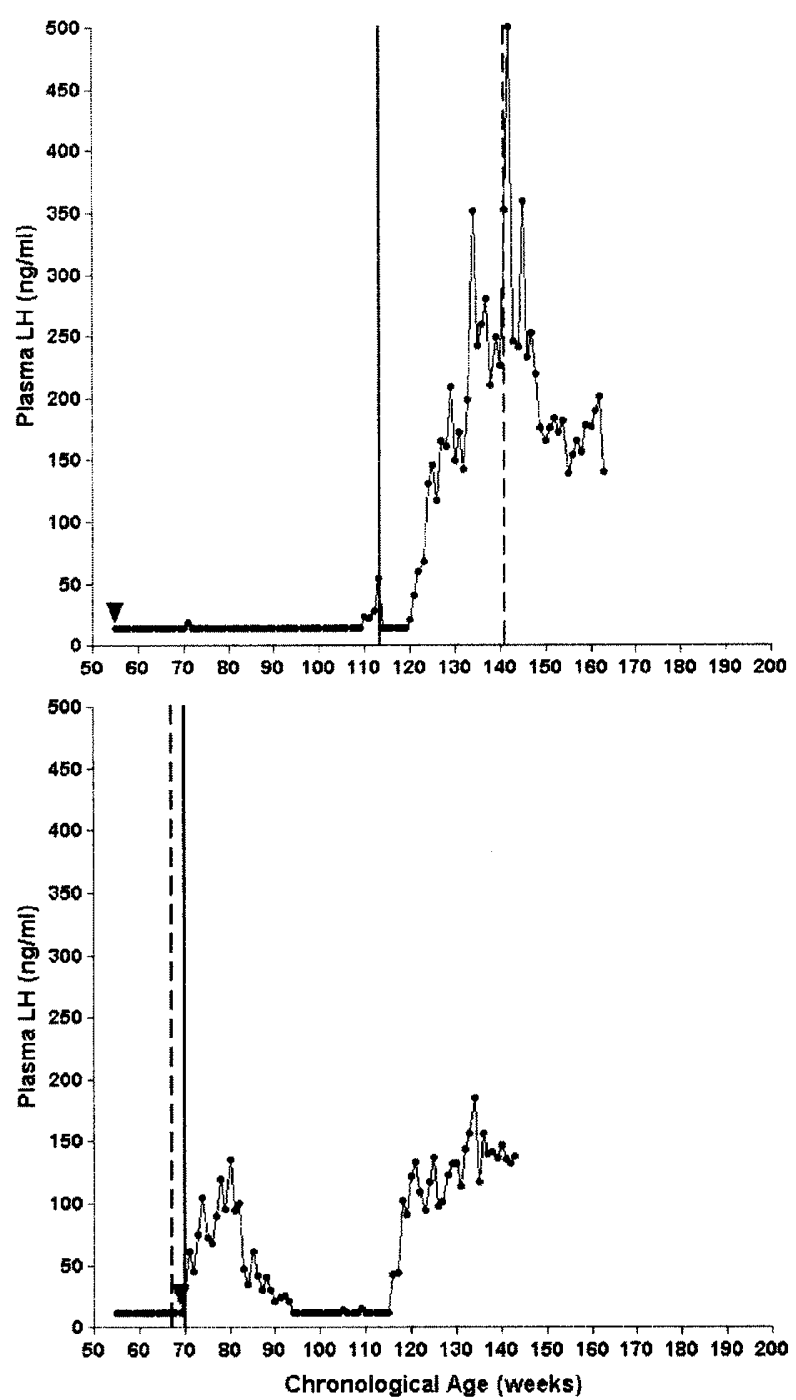

Effects of gonadal steroid treatments on linear body growth. As reflected by CRL, growth velocity in all three steroid-treated groups was significantly greater than that in the control animals ( $p<0.05$; Fig. 5). The pubertal CRL in $\mathrm{E}_{2^{-}}$ and T-treated groups $(68.0 \pm 2.3$ and $70.6 \pm 18.7 \mathrm{wk}$, respectively) was achieved at a significantly earlier CA than in the control group $(125.0 \pm 10.0 \mathrm{wk} ; p<0.05)$. Although the DHT-treated animals attained pubertal CRL earlier than the control animals $(75.5 \pm 20.5$ versus $125.0 \pm 10.0 \mathrm{wk})$, the difference was not significant.

Interactions between somatic indices and pubertal resurgence in LH secretion. The steroid-treated and control animals attained, on average, a pubertal BA at $85.3 \pm 8.9$ wk of CA, and this was significantly earlier $(p<0.05)$ than $\mathrm{CA}$ at pubertal LH resurgence $(117.7 \pm 8.9 \mathrm{wk})$. Linear regression analysis failed to reveal a direct relationship between BA and CA of pubertal LH secretion $\left(r^{2}=0.07\right)$. However, a remarkably close association was observed between the onset of pubertal LH secretion and pubertal BA in two of the T-treated monkeys (M1979 and M2004), in which attainment of pubertal

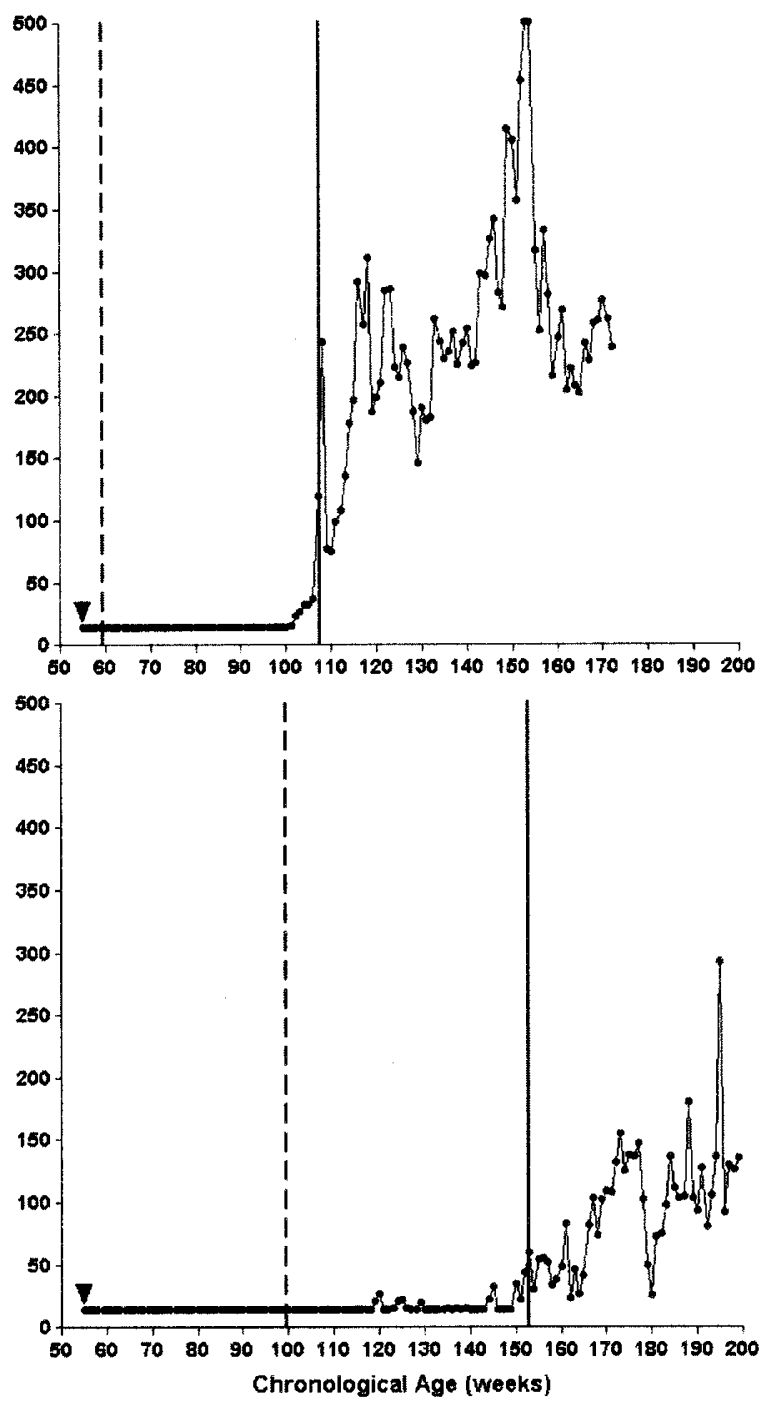

Figure 3. Plasma LH concentrations plotted against CA for a control animal (M1939; top left), an $\mathrm{E}_{2}$-treated animal (M1924; top right), a T-treated animal (M2004; bottom left), and a DHT-treated animal (M1921; bottom right). The arrowheads indicate the time of capsule removal (55 wk for control, $\mathrm{E}_{2}$, and DHT; $70 \mathrm{wk}$ for T). The solid vertical lines denote the time of pubertal LH resurgence. The dashed vertical lines indicate the age at which the pubertal BA was achieved. 


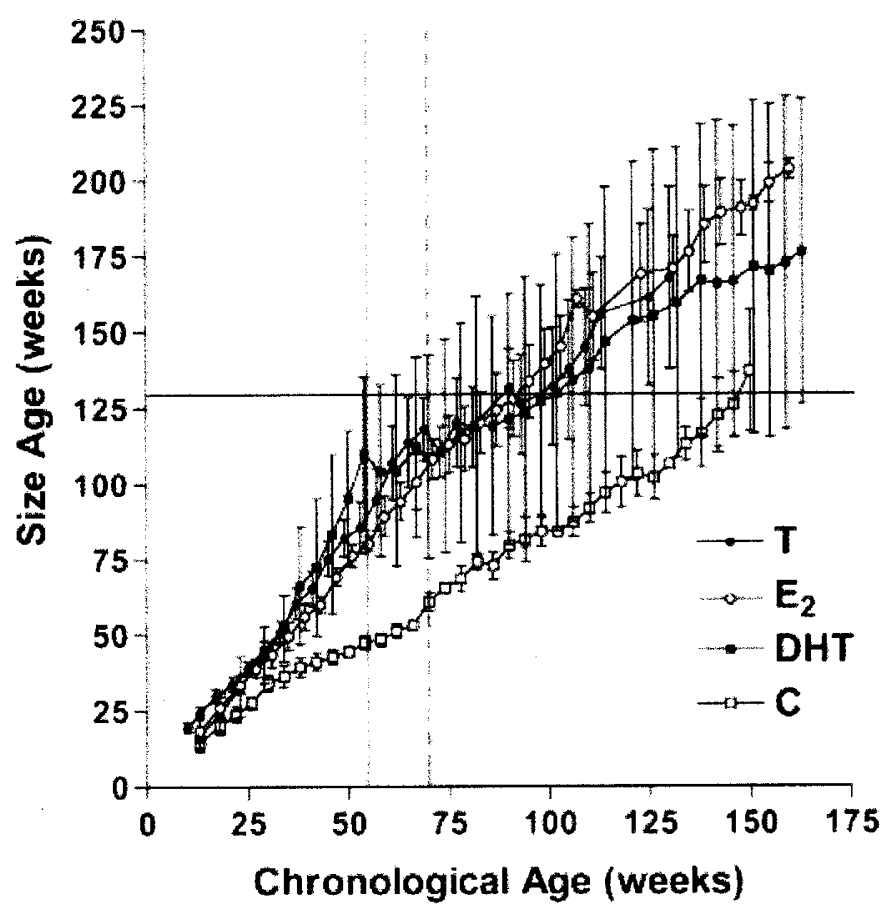

Figure 4. Mean ( \pm SEM) SA from 10 to up to $165 \mathrm{wk}$ of CA for agonadal

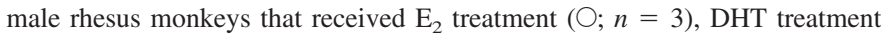
( $\square ; n=3$ until wk 118), or blank capsules (C; $\square ; n=3$ until wk 72) from $1-3$ to $55 \mathrm{wk}$ of age or T treatment $(-n=3)$ from $1-3$ to $70 \mathrm{wk}$ of age. The vertical lines indicate the CAs at the times of treatment cessation (solid $=55$ $\mathrm{wk}$, dashed $=70 \mathrm{wk}$ ). The horizontal line represents the target pubertal SA of 130 wk. The slope of the regression of SA upon CA during treatment with $\mathrm{E}_{2}$, $\mathrm{T}$, or DHT was significantly different $(p<0.05)$ from that of control (blank capsules, C).

BA at 68 and 67 wk of age was immediately followed by a progression into puberty at 76 and $70 \mathrm{wk}$ of age, respectively.

$\mathrm{CA}$ at attainment of pubertal SA for steroid-treated and control animals was not significantly different from CA of pubertal LH secretion $(107.8 \pm 13.8$ versus $117.7 \pm 8.9 \mathrm{wk})$. Moreover, linear regression revealed a significant relationship between CA at pubertal SA and CA at pubertal LH secretion ( $p$ $<0.05$; Fig. 6). Conversely, the average $\mathrm{CA}$ at attainment of pubertal CRL was significantly different from CA of pubertal LH secretion for treated and control animals $(p<0.05)$. Furthermore, the linear regression of CA at pubertal CRL on $\mathrm{CA}$ at pubertal $\mathrm{LH}$ secretion was not significant $\left(r^{2}=0.23\right.$; Fig. 7). It is interesting to note that in all three T-treated animals, a highly significant correlation was observed between the CA of pubertal LH secretion and CA at the attainment of both pubertal SA and pubertal CRL (slope: 1.08 and 0.86, respectively; $r^{2}=0.99$ in both cases; $p<0.05$ ), irrespective of the CA at which pubertal BA was attained (Table 1).

\section{DISCUSSION}

As expected, in the present study, skeletal maturation in the control animals proceeded in a linear manner from early infancy throughout the 3-y observation period, attaining plateau BA values of $\sim 130$ wk at a CA of between 125 and 130 wk. Treatment with $\mathrm{E}_{2}$ or the estrogen precursor $\mathrm{T}$ during the first year of life markedly accelerated skeletal maturation

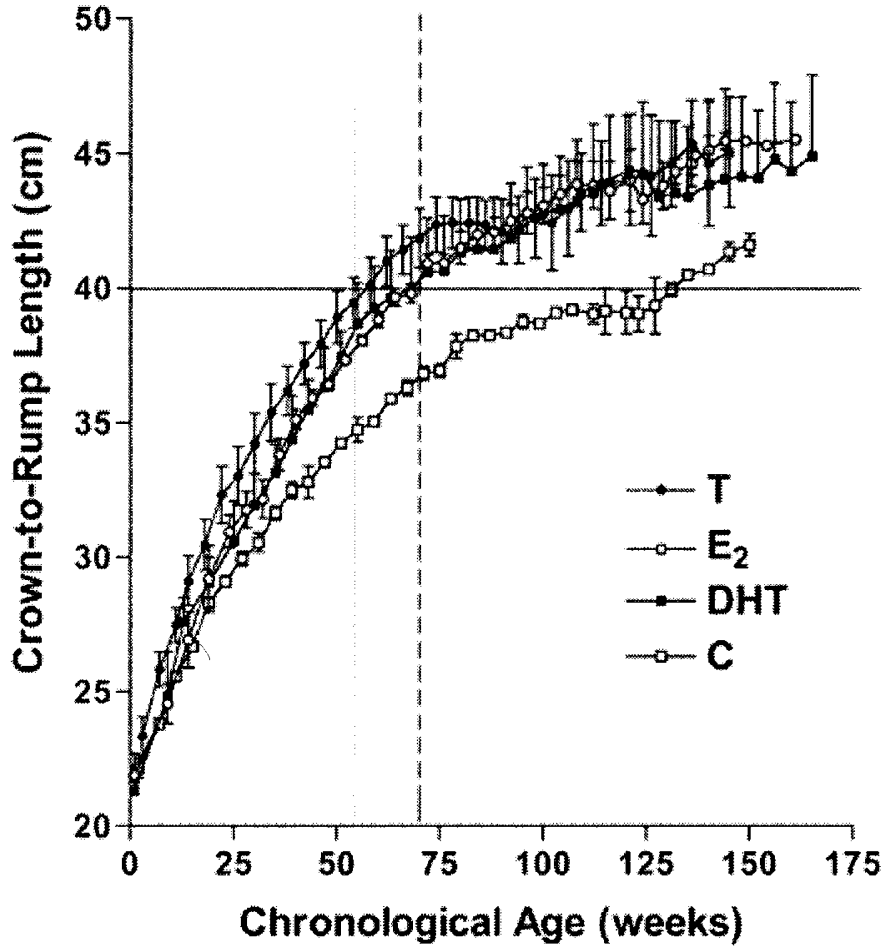

Figure 5. Mean ( \pm SEM) CRL from birth through the third year of life in agonadal male rhesus monkeys that received $\mathrm{E}_{2}$ treatment $(\bigcirc ; n=3)$, DHT treatment ( $\square ; n=3$ until wk 118), or blank capsules (C; $\square ; n=3$ until wk 72) from $1-3$ to $55 \mathrm{wk}$ of age or T treatment $(\mathbf{0} ; n=3)$ from $1-3$ to $70 \mathrm{wk}$ of age. The vertical lines indicate the $\mathrm{CA}$ at the time of treatment cessation ( solid $=55 \mathrm{wk}$, dashed $=70 \mathrm{wk}$ ). The horizontal line represents the target pubertal CRL $(40 \mathrm{~cm})$. The slope of the regression of CRL upon CA during treatment with $\mathrm{E}_{2}, \mathrm{~T}$, or DHT was significantly different $(p<0.05)$ from that of control (blank capsules, C).

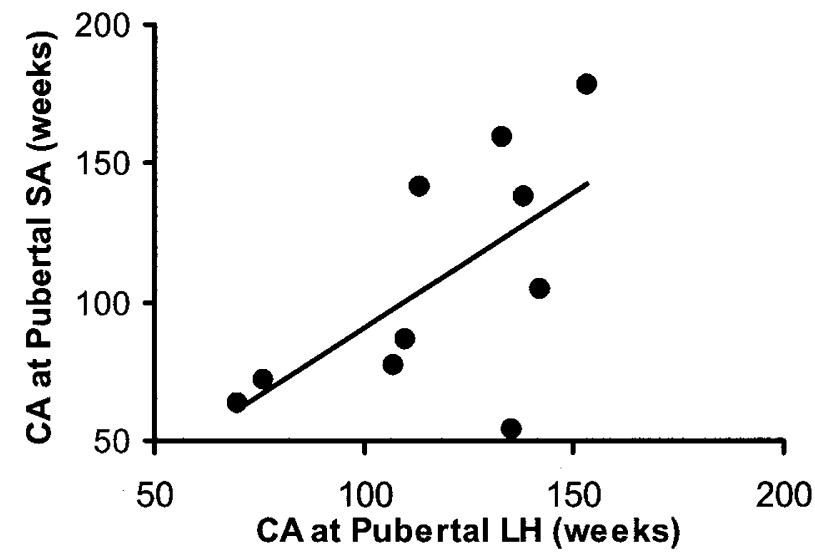

Figure 6. The relationship between the CAs at attainment of pubertal SA and resurgence of pubertal LH secretion $\left(\mathrm{y}=0.98 \times-7.30 ; r^{2}=0.39 ; p<0.05\right)$ in steroid-treated $\left(\mathrm{E}_{2}, \mathrm{~T}\right.$, and DHT) and control male agonadal rhesus monkeys.

during the phase of steroid administration. Even though $\mathrm{E}_{2}$ treatment was discontinued a few weeks prematurely, the BAs of each of the $\mathrm{E}_{2}$-treated animals, like those of the T-treated monkeys, had, by 67-71 wk of CA, progressed to or exceeded the target pubertal BA of 130 wk. In striking contrast, a comparable period of treatment with the nonaromatizable androgen DHT, which produced plasma DHT levels similar to those observed for $\mathrm{T}$ during $\mathrm{T}$ treatment, failed to accelerate 


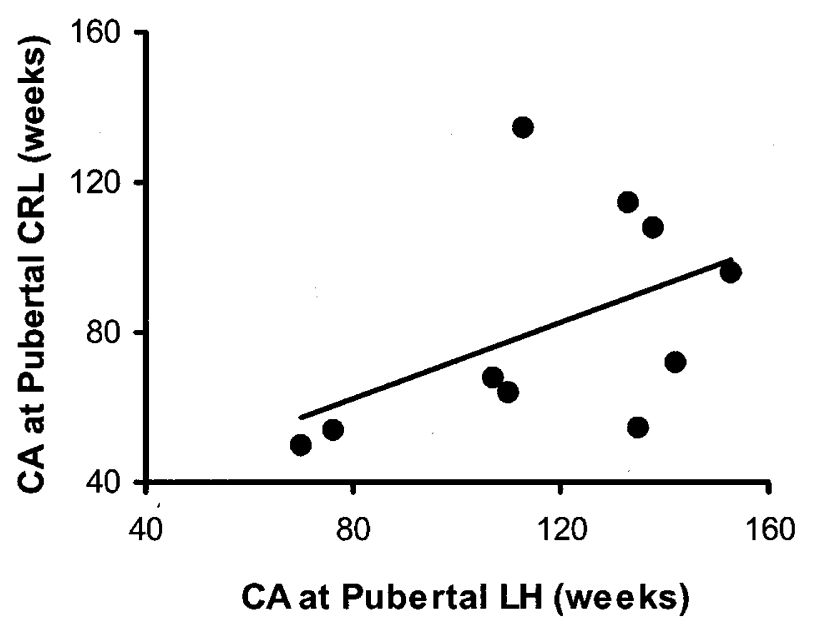

Figure 7. The relationship between the CAs at attainment of pubertal CRL and resurgence of pubertal LH secretion $\left(\mathrm{y}=0.51 \times \pm 21.9 ; r^{2}=0.2274 ; p\right.$ $>0.05)$ in steroid-treated $\left(\mathrm{E}_{2}, \mathrm{~T}, \mathrm{DHT}\right)$ and control male agonadal rhesus monkeys.

Table 1. Relationship between $C A$ at resurgence of pubertal LH secretion and attainment of pubertal BA, SA, and CRL in agonadal male rhesus monkeys treated with $T$ from 1-3 to 70 wk of age

\begin{tabular}{lcccc}
\hline & $\begin{array}{c}\text { CA at pubertal } \\
\text { LH secretion } \\
\text { (wk) }\end{array}$ & $\begin{array}{c}\text { CA at pubertal } \\
\text { SA (wk) }\end{array}$ & $\begin{array}{c}\text { CA at pubertal } \\
\text { CRL (wk) }\end{array}$ & $\begin{array}{c}\text { CA at pubertal } \\
\text { BA (wk) }\end{array}$ \\
\hline M1978 & 138 & 138 & 108 & 64 \\
M1979 & 76 & 72 & 54 & 69 \\
M2004 & 70 & 64 & 50 & 67
\end{tabular}

BA. These findings suggest that $E_{2}$ is the steroid responsible for skeletal maturation in the rhesus monkey and are consistent with several clinical observations. First, patients with mutations of the genes encoding estrogen receptor (ER) $(25,26)$ and aromatase $(27,28)$ exhibit retarded bone maturation. Second, epiphyseal maturation is more rapid in female individuals, and this has been attributed by some to higher $\mathrm{E}_{2}$ levels in prepubertal girls than in prepubertal boys (29). The latter view, however, has been challenged (30).

Although DHT failed to promote bone maturation in juvenile monkeys during the 55-wk treatment period, withdrawal of this pure androgen led to an acceleration in BA equivalent to that observed in the $\mathrm{E}_{2}$ and $\mathrm{T}$ treatment groups during steroid administration. As a consequence, the attainment of a pubertal BA (87 wk of CA) was also advanced in the DHT-treated monkeys. At the end of the study period, the rank order of the mean BA ages by treatment was $\mathrm{E}_{2}>\mathrm{T}>\mathrm{DHT}>\mathrm{C}$, indicating that gonadal steroid treatment within the first year of life had permanent effects on skeletal maturation.

As expected, all gonadal steroids induced a significant advancement of SA during treatment. At the end of the experiment, there was little difference between the SA of the steroidtreated groups, whereas all were significantly heavier than control animals. After steroid withdrawal, the rate of progression of SA returned to the slope followed by the control group regardless of the SA attained during previous steroid treatment. Treatment with steroids also advanced linear growth.

Of particular interest was the finding that whereas $E_{2}$ or $T$ treatment resulted in an acceleration of body weight gain concomitantly with an increased rate of bone maturation, DHT administration accelerated body weight without advancing BA. This action of DHT to selectively accelerate somatic growth is supported by most but not all of the clinical data (31-37), indicating that oxandrolone, a synthetic nonaromatizable androgenic compound, is growth promoting in children. The posttreatment acceleration of bone maturation after withdrawal of DHT may be described as a "catch-up effect" and is somewhat reminiscent of catch-up growth in refed, nutritionally deprived children such as those with psychosocial dwarfism and other endocrinopathies, such as hypothyroidism and Cushing's syndrome $(38,39)$. The drive for the acceleration in BA after DHT withdrawal is unknown. It is reasonable to speculate, however, that it must be the product of the incongruent relationship between body size (large body weight and linear dimensions) and retarded skeletal maturation that was in existence at the time of DHT withdrawal. If this hypothesis is accepted, then it may also be proposed that during DHT treatment, when the incongruent relationship between BA and body weight was developing, the nonaromatizable steroid, in addition to its positive effect on body weight, may have exerted an inhibitory action on bone maturation. In this regard, it is interesting to note that DHT had a negative effect on proliferation and differentiation in a human fetal osteoblastic cell line expressing a physiologic number of androgen receptors (ARs) (40). It seems reasonable, therefore, to further propose that during prepubertal development, when gonadal steroid secretion is minimal, bone maturation may be linked primarily to somatic growth velocity.

It has been recently argued that, in humans, estrogen, in addition to being the primary signal for advancing BA, may be the critical steroid responsible for the pubertal linear growth spurt, as it has been reported that aromatase-deficient men had no "pubertal inflection" in their growth curves (41). Furthermore, patients with complete androgen insensitivity syndrome, in which ER is the only functional sex steroid receptor, show a pubertal growth spurt that is typical of normal individuals (42-44). Conversely, evidence that activation of AR may contribute to pubertal growth is indicated by numerous clinical studies showing the nonaromatizable androgens oxandrolone (33-37) and DHT $(45,46)$ to be as effective as T in promoting linear growth. Evidence also exists to suggest that exogenous estrogens do not initiate a complete growth spurt (47). Parenthetically, it should be noted that, in the present study, $\mathrm{E}_{2}$ treatment did not seem to restrict linear growth in agonadal male monkeys during the experimental period. Whether this observation indicates a significant difference in the $E_{2}$ effects on epiphyseal growth plate of the monkey and the human is yet to be ascertained.

ER and AR both are expressed in human epiphyseal plate and bone cells throughout pubertal development $(48,49)$. In this regard, DHT has been shown to stimulate DNA synthesis and cell proliferation in epiphyseal rat chondrocyte in primary culture (50), indicating a growth-promoting effect of this steroid on epiphyseal cartilage. A role of AR in the pubertal growth spurt is also supported by the present finding that DHT was equivalent in its effects on linear growth and other somatic growth indices to both $\mathrm{E}_{2}$ and $\mathrm{T}$. Therefore, unlike the case for 
$\mathrm{BA}$, where $\mathrm{E}_{2}$ may be the singular steroid responsible for pubertal bone maturation, both ER and AR probably play important roles in supporting the pubertal linear growth spurt.

In the present study, although BA was among the best correlates of the onset of the pubertal resurgence of LH release, this relationship was not statistically significant. Nevertheless, it is remarkable that two of the three T-treated monkeys exhibited a precocious resurgence in $\mathrm{LH}$ secretion $\sim 60 \mathrm{wk}$ before that in control monkeys but after attainment of a pubertal BA, by 4-6 wk. Moreover, the resurgence in LH secretion in these two animals was coincident with withdrawal of $\mathrm{T}$ treatment, and it therefore is possible that the potential for a pubertal mode of hypothalamic GnRH release was attained even earlier and was held in check by an inhibitory feedback action of $\mathrm{T}$. The reason for the transient 20- to 25 -wk interruption in the pubertal mode of LH secretion in these two animals is unclear but may be related to a decrease in body mass index (presumably as a result of loss of muscle mass after $\mathrm{T}$ withdrawal) that was noted in these two monkeys during the hiatus in LH secretion. GnRH-dependent precocious gonadarche in humans is often associated with advanced skeletal maturation in pathologies that result in early, chronic exposure to sex steroids, such as in adrenal hyperplasia (14) and familial testotoxicosis (15). In these disorders, treatment of the symptoms (eliminating the overproduction of androgens) reveals premature pubertal gonadotropin secretion in patients with a pubertal BA. More that 50 y ago, van Wagenen (51) demonstrated that exogenous $\mathrm{T}$ could induce precocious gonadarche in prepubertal female monkeys. In that study, $\mathrm{T}$ administration starting at 5 mo of age resulted in precocious menarche accompanied by accelerated growth. It is noteworthy that the T-treated animals in this early experiment attained a body weight and length comparable to 2-y-old monkeys at the time of menarche, which occurred at a CA of $1 \mathrm{yr}$. A role of BA in regulating the timing of the pubertal resurgence in $\mathrm{GnRH}$ release is also suggested by the observation that, in children with true isolated growth hormone deficiency (17), sexual maturation occurs late for CA but at a normal pubertal BA. Although in the present investigation, the attainment of a pubertal BA was not necessarily associated with progression into puberty, in 9 of the 10 animals that completed the study, attainment of a pubertal BA preceded the pubertal resurgence of LH secretion. These observations suggest that attainment of a pubertal BA may be a prerequisite but not sufficient for triggering the onset of the normal pubertal process.

Finally, the present data indicate that, in the male monkey, SA may be more tightly coupled to the onset of pubertal $\mathrm{LH}$ secretion than either BA or linear growth. Cross-sectional and longitudinal studies in the human are also indicative of a strong association of weight status with the timing of the onset of puberty in both sexes (52-56). Individuals with higher body mass at a certain age had an earlier onset of puberty. Although the precise physiologic mechanisms underlying this association between somatic growth and puberty remain unknown, the tantalizing relationship between indices of somatic development on the one hand and the onset of pubertal LH secretion on the other is consistent with the idea that a circulating cue(s) reflecting somatic maturation may serve as a signal to the hypothalamus to regulate the resurgence of pulsatile $\mathrm{GnRH}$ release and, therefore, the timing of gonadarche.

Acknowledgments. We thank Dr. Peter A. Lee, Milton S. Hershey Medical Center, for guidance in assessing BA.

\section{REFERENCES}

1. Witchel SF, Plant TM 2004 Puberty: gonadarche and adrenarche. In: Strauss JF III, Barbieri R (eds) Yen and Jaffe's Reproductive Endocrinology, 5th Ed. W.B. Saunders Co., Orlando, pp 493-535

2. Plant TM 1994 Puberty in primates. In: Knobil E, Neill JD (eds) The Physiology of Reproduction, 2nd Ed., Vol 2. Raven Press, New York, pp 453-485

3. Bullough WS 1951 Vertebrate Sexual Cycles. Methuen, London

4. Plant TM, Fraser MO, Medhamurthy R, Gay VL 1989 Somatogenic control of GnRH neuronal synchronization during development in primates: a speculation. In: Delamarre-van de Waal HA, Plant TM, van Rees GP, Schoemaker J (eds) Control of the Onset of Puberty III, Excerpta Medica, Amsterdam, pp 111-121

5. Frisch RE, Revelle R 1970 Height and weight at menarche and a hypothesis of critical body weights and adolescent events. Science 169:397-399

6. Steiner RA, Cameron JL, McNeill TH, Clifton DK, Bremner WJ 1983 Metabolic signals for the onset of puberty. In: Norman RL (ed) Neuroendocrine Aspects of Reproduction. Academic Press, New York, pp 183-227

7. Marshall WA 1974 Interrelationships of skeletal maturation, sexual development and somatic growth in man. Ann Hum Biol 1:29-40

8. Simmons K, Greulich WW 1943 Menarcheal age and the height, weight, and skeletal age of girls age 7 to 17 years. J Pediatr 22:518-548

9. Acheson RM 1954 A method of assessing skeletal maturity from radiographs. J Anat 88:498-508

10. Tanner JM, Whitehouse RH, Healy MJR 1962 A New System for Estimating Skeletal Maturity from the Hand and Wrists, with Standards Derived from a Study of 2,600 Healthy British Children. International Children's Centre, Paris

11. Garn SM, Poznanski AK, Nagy JM 1971 The operational meaning of maturity criteria. Am J Phys Anthropol 35:319-325

12. Michejda M 1987 Skeletal Development of the Wrist and Hand in Macaca mulatta and Man. Karger, New York

13. Styne DM, Grumbach MM 1978 Puberty in the male and female: its physiology and disorders. In: Yen SSC, Jaffe RB (eds) Reproductive Endocrinology. WB Saunders Co., Philadelphia, p 189

14. Frasier SD 1980 Pediatric Endocrinology. Grune and Stratton, New York, p 172

15. Flor-Cisneros A, Leschek EW, Merke DP, Barnes KM, Coco M, Cutler GB Jr, Baron J 2004 In boys with abnormal developmental tempo, maturation of the skeleton and the hypothalamic-pituitary-gonadal axis remains synchronous. J Clin Endocrinol Metab 89:236-241

16. Holland FJ, Kirsch SE, Selby R 1987 Gonadotropin-independent precocious puberty ("testotoxicosis"): influence of maturational status on response to ketoconazole. J Clin Endocrinol Metab 64:328-333

17. Tanner JM, Whitehouse RH 1975 A note on the bone age at which patients with true isolated growth hormone deficiency enter puberty. J Clin Endocrinol Metab 41:788-790

18. Epstein S 1988 Serum and urinary markers of bone remodeling: assessment of bone turnover. Endocr Rev 9:437-449

19. Poole AR, Rosenberg LC 1986 Chondrocalcin and the calcification of cartilage. A review. Clin Orthop 208:114-118

20. Plant TM 1985 A study of the role of the postnatal testes in determining the ontogeny of gonadotropin secretion in the male rhesus monkey (Macaca mulatta). Endocrinology 116:1341-1350

21. Plant TM, Hess DL, Hotchkiss J, Knobil E 1978 Testosterone and the control of gonadotropin secretion in the male rhesus monkey (Macaca mulatta). Endocrinology 103:535-541

22. Fraser MO, Pohl CR, Plant TM 1989 The hypogonadotropic state of the prepubertal male rhesus monkey (Macaca mulatta) is not associated with a decrease in hypothalamic gonadotropin releasing hormone content. Biol Reprod 40:972-980

23. Hotchkiss J, Atkinson LE, Knobil E 1971 Time course of serum estrogen and luteinizing hormone $(\mathrm{LH})$ concentrations during the menstrual cycle of the Rhesus monkey. Endocrinology 89:177-183

24. Suter KJ, Pohl CR, Plant TM 1998 The pattern and tempo of the pubertal reaugmentation of open-loop pulsatile gonadotropin-releasing hormone release assessed indirectly in the male rhesus monkey (Macaca mulatta). Endocrinology 139:2774-2783

25. Smith EP, Boyd J, Frank GR, Takahashi H, Cohen RM, Specker B, Williams TC, Lubahn DB, Korach KS 1994 Estrogen resistance caused by a mutation in the estrogen-receptor gene in a man. N Engl J Med 331:1056-1061

26. Korach KS, Couse JF, Curtis SW, Washburn TF, Lindzey J, Kimbro KS, Eddy EW, Migliaccio S, Snedeker SM, Lubahn DB, Schomberg DW, Smith EP 1996 Estrogen receptor gene disruption: molecular characterization and experimental and clinical phenotypes. Recent Prog Horm Res 51:159-186

27. Morishima A, Grumbach MM, Simpson ER, Fisher C, Qin K 1995 Aromatase deficiency in male and female siblings caused by a novel mutation and the physiological role of estrogens. J Clin Endocrinol Metab 80:3689-3698

28. Carani C, Qin K, Simoni M, Faustini-Fustini M, Serpente S, Boyd J, Korach KS, Simpson ER 1997 Effect of testosterone and estradiol in a man with aromatase deficiency. N Engl J Med 337:91-95

29. Cutler GB Jr 1997 The role of estrogen in bone growth and maturation during childhood and adolescence. J Steroid Biochem Mol Biol 61:141-144 
30. Lee PA, Witchel SF 1997 The influence of estrogen on growth. Curr Opin Pediatr 9:431-436

31. Danowski TS, Lee FA, Cohn RE, D'Ambrosia RD, Limaye NR 1965 Oxandrolone therapy of growth retardation. Am J Dis Child 109:526-532

32. Ray CG, Kirschvink JF, Waxman SH, Kelly VC 1965 Studies of anabolic steroids. 3 The effect of oxandrolone on height and skeletal maturation in mongoloid children. Am J Dis Child 110:618-623

33. Urban MD, Lee PA, Doest JP, Plotnick LP, Migeon CJ 1979 Oxandrolone therapy in patients with Turner syndrome. J Pediatr 94:823-827

34. Stanhope R, Brook CG 1985 Oxandrolone in low dose for constitutional delay of growth and puberty in boys. Arch Dis Child 60:379-381

35. Clayton PE, Shalet SM, Price DA, Addison GM 1988 Growth and growth hormone responses to oxandrolone in boys with constitutional delay of growth and puberty (CDGP). Clin Endocrinol 29:123-130

36. Jackson ST, Rallison ML, Buntin WH, Johnson SB, Flynn RR 1973 Use of oxandrolone for growth stimulation in children. Am J Dis Child 126:481-484

37. Romshe CA, Sotos JF 1980 The combined effect of growth hormone and oxandrolone in patients with growth hormone deficiency. J Pediatr 96:127-131

38. Savage MO, Scommegna S, Carroll PV, Ho JT, Monson JP, Besser GM, Grossman AB 2002 Growth in disorders of adrenal hyperfunction. Horm Res 58(suppl 1):39-43

39. Tanner JM, Whitehouse RH 1982 Atlas of Children's Growth. Normal Variation an Growth Disorders. Academic Press, New York

40. Hofbauer LC, Hicok KC, Khosla S 1998 Effects of gonadal and adrenal androgens in a novel androgen-responsive human osteoblastic cell line. J Cell Biochem 71:96-108

41. Grumbach MM, Auchus RJ 1999 Estrogen: consequences and implications of human mutations in synthesis and action. J Clin Endocrinol Metab 84:4677-4694

42. Frank GR 2003 Role of estrogen and androgen in pubertal skeletal physiology. Med Pediatr Oncol 41:217-22

43. Grumbach MM 2000 Estrogen, bone, growth and sex: a sea change in conventional wisdom. J Pediatr Endocrinol Metab 13(suppl 6):1439-1455

44. Marcus R, Leary D, Schneider DL, Shane E, Favus M, Quigley CA 2000 The contribution of testosterone to skeletal development and maintenance: lessons from the androgen insensitivity syndrome. J Clin Endocrinol Metab 85:1032-1037
45. Keenan BS, Richards GE, Ponder SW, Dallas JS, Nagamani M, Smith ER 1993 Androgen-stimulated pubertal growth: the effects of testosterone and dihydrotestosterone on growth hormone and insulin-like growth factor-I in the treatment of short stature and delayed puberty. J Clin Endocrinol Metab 76:996-1001

46. Keenan BS, Richards GE, Mercado M, Dallas JS, Eakman GD, Baumann G 1996 Androgen regulation of growth hormone binding protein. Metabolism 45:15211526

47. Delemarre-van de Waal HA, van Coeverden SC, Rotteveel J 2001 Hormonal determinants of pubertal growth. J Pediatr Endocrinol Metab 14(suppl 6):1521-1526

48. Nilsson O, Chrysis D, Pajulo O, Boman A, Holst M, Rubinstein J, Martin Ritzen E, Savendahl L 2003 Localization of estrogen receptors-alpha and -beta and androgen receptor in the human growth plate at different pubertal stages. J Endocrinol 177:319326

49. Saggese G, Bertelloni S, Baroncelli GI 1997 Sex steroids and the acquisition of bone mass. Horm Res 48(suppl 5):65-71

50. Krohn K, Haffner D, Hugel U, Himmele R, Klaus G, Mehls O, Schaefer F 2003 1,25 $(\mathrm{OH})_{2} \mathrm{D}_{3}$ and dihydrotestosterone interact to regulate proliferation and differentiation of epiphyseal chondrocytes. Calcif Tissue Int 73:400-410

51. van Wagenen G 1949 Accelerated growth with sexual precocity in female monkeys receiving testosterone propionate. Endocrinology 45:544-546

52. Power C, Lake JK, Cole TJ 1997 Body mass index and height from childhood to adulthood in the 1958 British born cohort. Am J Clin Nutr 66:1094-1101

53. Lee MM, Sergeyev O, Williams P, Korrick S, Zeilert V, Revich B, Hauser R 2003 Physical growth and sexual maturation of boys in Chapaevsk, Russia. J Pediat Endocrinol Metab 16:169-178

54. Mul D, Fredriks AM, van Buuren S, Oostdijk W, Verloove-Vanhorick SP, Wit JM 2001 Pubertal development in The Netherlands 1965-1997. Pediatr Res 50:479-486

55. Davison KK, Susman EJ, Birch LL 2003 Percent body fat at age 5 predicts earlier pubertal development among girls at age 9. Pediatrics 111:815-821

56. Klentrou P, Plyley M 2003 Onset of puberty, menstrual frequency, and body fat in elite rhythmic gymnasts compared with normal controls. Br J Sports Med 37:490494 